\title{
COOPERAÇÃO E COMPETIÇÃO ENTRE EMIGRANTES BRASILEIRAS
}

\author{
Soraya Fleischer*
}

\section{EMIGRAÇÃO BRASILEIRA INTERNACIONAL}

Como já foi amplamente mostrado pela mídia e pela literatura acadêmica, desde a década de 1970, o Brasil tem apresentado um perfil emigracionista $\mathrm{e}$ vem se incorporando ao conjunto das nações que abastecem o mercado primeiro-mundista com trabalhadores braçais. Nas últimas décadas do século, ou no chamado "triênio da desilusão" (Sales, 1999, p.32), o desânimo com as políticas econômicas, a falta de perspectiva de ascensão social e a desesperança foram os principais motivos para a saída dos brasileiros (Assis, 1999, Torresan, 1994, Sasaki, 1999). Assim, a literatura define nossos emigrantes como, prioritariamente, "exilados da crise" ou "refugiados econômicos".

É importante inserirmos o caso brasileiro no contexto atual das migrações internacionais (Margolis, 1994). Apesar dos brasileiros se distinguirem do padrão do migrante pobre, pouco instruído e pouco qualificado profissionalmente, também estão na condição de migrantes ilegais ou não-documentados e suprem a demanda do mercado secundário e informal. Devido à ilegalidade e ao desconhecimento da língua, eles vão ingressar nos escalões mais baixos da pirâmide de trabalho e constituir uma mão-deobra subvalorizada, sub-remunerada e submissa. Os estudos sobre os dekasseguis resumem o perfil destas ocupações com os " $3 \mathrm{~K}$ ": kitanai (sujo), kiken (perigoso) e kitsui (penoso) (Sasaki, 1999). Além disso, estes emigrantes se inserem no contexto polêmico e explosivo das medidas restricionistas e xenofóbicas contra estrangeiros.

\section{RECORTE ETNOGRÁFICO}

Sempre vemos nos noticiários histórias de brasileiras que deixam o país para limpar casas de norte-americanos e europeus. Por que esta opção é tão recorrente? Esta foi a pergunta que norteou minhas reflexões para a tese de mestrado em Antropologia Social na Universidade de Brasília. Fui até esta realidade para conhecê-la melhor. Durante quatro meses, morei e convivi com 42 mulheres que trabalhavam em Boston, Massachussets, como housecleaners ${ }^{1}$, ou melhor, faxineiras (Fleischer, 2000b). A pesquisa que embasa este artigo foi realizada com 70 entrevistas, observações das faxinas e convívio social na comunidade brasileira. A pesquisa etnográfica aproxima e materializa as vozes destas brasileiras.

Neste artigo, pretendo mostrar como, dentro do mercado de limpeza doméstica, estas brasileiras estabelecem ora re- lações de cooperação ora de competição com suas conterrâneas. Os arranjos de trabalho que vêm criando oferecem material bastante rico para pensarmos como estas relações sociais estão criando a comunidade brasileira dentro do contexto da migração internacional.

\section{COMEÇANDO UM BUSINESS DE HOUSECLEANING}

Quando os brasileiros ouvem de seus parentes e amigos que emigraram para os EUA que o salário mínimo é de 5 dólares a hora, fazem as contas e decidem deixar os 180 reais do Brasil, para ganhar, no mínimo, 800 dólares por mês no novo país. Assim que podem, deixam os trabalhos comuns entre migrantes laborais (baby-sitters, entregadores de jornal, dichas ${ }^{2}$, etc.) para investir em um negócio próprio. O housecleaning vem sendo uma escolha recorrente entre as brasileiras em Boston devido a boa remuneração, autonomia, controle do tempo e jornada, a familiaridade e legitimidade do serviço, a segurança de estar dentro de uma casa, o contato com os valores norte-americanos e a pouca necessidade do inglês por se tratar de uma atividade braçal.

Geralmente, a entrada no ramo se dá como funcionária de uma empresa de limpeza, em geral americana, ou como 
ajudante de outra brasileira que tem muitas casas para limpar. É nesta fase inicial que ela adquire os conhecimentos básicos sobre limpeza e consegue construir uma pequena poupança. Depois que esta ajudante reúne os pré-requisitos mínimos para trabalhar sozinha, ela deixa a "patroa" e inaugura seu próprio negócio. Portanto, neste momento, ela deve ter carteira de motorista, carro, clientela, léxico mínimo de inglês e da cultura americana e saber fazer faxina.

As entrevistadas freqüentemente se definiam como "donas do trabalho", isto é, a cleaner que já sobrevive do próprio business formado por uma clientela mínima que vai crescendo e se consolidando com sua competência ao longo do tempo. Dona do trabalho é um termo usado para diferenciar a housecleaner da cliente, que é a dona da casa.

\section{A COOPERAÇÃO ENTRE DONAS DO TRABALHO}

Há várias formas de cooperação entre duas housecleaners. Quando uma dona do trabalho tem algum contratempo e não pode limpar suas casas, ela procura uma colega que a substitua. Ela pode fazer isto na véspera ou, de preferência, com alguns dias de antecedência. Antes, porém, ela precisa consultar suas clientes. Caso concordem, ela então repassa chaves e endereços à substituta e lhe ensina como deve ser feito o trabalho. As casas que não aceitarem a substituta terão que ser canceladas e adiadas para a semana seguinte.

Em caso de ausências mais prolongadas, é melhor que, antes de partir, a cleaner oficial encontre alguém de confiança e empreste as casas. Isto porque, a oficial não pode correr o risco de voltar de viagem e não ter mais o seu sustento. O repasse é semelhante ao indicado no parágrafo acima. É preciso que fique claro que a substituta não é caracterizada como uma ajudante, mas como a housecleaner responsável pelas casas na ausência da oficial. Nestas ocasiões, a substituta tem a oportunidade de apren- der o serviço e o trato com as clientes americanas, duas condições fundamentais que lhe permitirão, após o retorno da colega, começar seu próprio business.

Duas housecleaners também podem se auxiliar se uma tiver um schedule ${ }^{3}$ cheio e aceitar passar casas menos interessantes para suas colegas que estejam iniciando seus próprios negócios. "Passar" pode significar dar ou vender o trabalho realizado na casa. Em ambos os casos, a cleaner oficial informa sua cliente da descontinuidade do trabalho e que uma colega vai substituí-la. Mas, no segundo caso, esta transferência de posto de trabalho recebe um preço que a nova cleaner deve pagar para receber a chave, o endereço, os macetes do serviço e ser apresentada à cliente. ${ }^{4}$

Os depoimentos mostram que um dos motivos mais recorrentes para se emprestar o schedule são as férias passadas no Brasil. Somente os migrantes com green cards $^{5}$ ou aqueles que não são overstayers $^{6}$ podem ir e vir livremente de um país a outro. Se a housecleaner titular estivesse indo definitivamente para o Brasil, poderia vender ou dar suas casas porque não estaria pensando em voltar aos EUA. Mas apesar de toda ida ao Brasil reavivar a esperança de poder ficar novamente, esta realidade é incerta e a migrante precisa deixar seu schedule de forma que possa retomá-lo se voltar. Emprestá-lo é uma forma de garantir sua fonte de renda nos EUA.

Eugênia ${ }^{7}$ salienta que, em ambos os casos, uma housecleaner íntegra precisa ensinar os macetes das faxinas e as manias das clientes para que as três mulheres fiquem satisfeitas: para que a vendedora não tenha seu nome sujo na praça, a compradora consiga ser competente e manter seu novo schedule e a cliente continue recebendo um bom serviço. Tanto no empréstimo quanto na venda de casas, a novata espera que a cliente aprove seu serviço, afinal, no primeiro caso, as casas já estão pagas e ela não pode correr o risco de perdê-las. $\mathrm{E}$, no segundo caso, a novata precisa ser eficiente para manter intacto o schedule de sua amiga; no entanto, o efeito desta eficiência pode ser justamente o contrário: a cliente pode preferir a substituta e impedir que a oficial retome a casa. A escolha da cliente é o que vale. No caso do empréstimo que virou uma doação involuntária, o que era, a princípio, cooperação, pode terminar como constrangimento entre as amigas.

Outra alternativa é duas donas do trabalho trocarem serviços. Ao invés de contratar e treinar uma ajudante e correr o risco da cliente não a aprovar, de ter algo nas casas roubado ou quebrado e de perder a ajudante assim que ela encontrar um trabalho melhor, Cristina e Carolina preferiram a cooperação mútua. Elas tinham dias com poucas casas e resolveram trabalhar juntas. Na parte da manhã, uma dona do trabalho virava ajudante da outra. E, na parte da tarde, a situação se invertia. Esta saída só funciona para schedules menores ou complementares, em termos de horários e quantidade de serviço. E, o mais importante, é preciso haver reciprocidade, porque esta "ajuda" não é paga: o trabalho oferecido à colega deve equivaler ao recebido da mesma e, dentro das casas, elas precisam trabalhar igualmente. Este arranjo é interessante por envolver menos hierarquia e exploração, ingredientes tão presentes na relação típica entre dona do trabalho e ajudante. Reverter imediatamente a subordinação ameniza uma possível distância ou superioridade. E a amizade também ajuda a conter estas desigualdades.

Caso ambas housecleaners têm schedules grandes demais para trocarem serviços, podem optar por dividir uma ajudante. Assim, a funcionária trabalhará com uma dois dias na semana e os demais com a outra. Este arranjo permite que as duas donas do trabalho dêem conta da demanda de serviço, compartilhem experiências para resolver os conflitos comuns com ajudantes e exerçam maior controle sobre esta mão-de-obra.

A maneira mais comum de cooperação é a sociedade. A maioria das 42 en- 
trevistadas tinha sócios. Há três maneiras de uma sociedade ser formada: duas brasileiras podem começar um business juntas, podem unir seus negócios ou então uma pode ingressar como sócia de outra, previamente estabelecida no ramo. Estes tipos de sociedade são interessantes por razões diferentes. No primeiro caso, os pré-requisitos de uma cleaner serão complementados pelos da outra. No segundo caso, a sociedade resultaria na soma dos dois schedules. Já o terceiro caso, ao invés de contratar uma ajudante para dar conta de um schedule muito grande, uma boa saída é encontrar uma sócia. Os novatos sempre precisarão aprender as técnicas do ramo enquanto cleaners experientes terão que aprender a equilibrar experiências, estilos e expectativas diferentes. Em todos os casos, uma sócia significa a possibilidade de ter mais casas para limpar e mais renda. A vantagem é que não só a renda será dividida, mas, principalmente, tempo, problemas e exigências do ramo.

Uma housecleaner não chama qualquer pessoa para dividir um negócio, há uma hierarquia de candidatos. Primeiro ela convida parentes, depois afins e, por último, conhecidos ou, simplesmente, conterrâneos que estejam desempregados. Os interesses e as posições da dona do trabalho e da ajudante são necessariamente diferentes, por isso, é mais comum que parentes comecem como sócios e os demais como ajudantes. À época da pesquisa, encontrei sociedades entre cônjuges, mães e filhos, irmãs, irmãos, primas, tias e sobrinhas e amigas. Ester e Noemi, respectivamente, argumentam porque a sociedade em família é interessante e eficaz:

"A minha mãe nunca quis pessoas de fora, ela sempre quis manter o negócio entre família. Uma porque família tá sempre querendo ajudar um ao outro. Outra porque americano é muito desconfiado, "eu quero saber como vocês vivem". Americano preserva muito isso. Tanto que a carta que a gente manda diz que a gente trabalha em fa- mília".

"Porque os dois sócios já sabem o que precisam ganhar e o trabalho é junto, um depende do outro, então divide com facilidade isso. E quando é um estranho, a pessoa não tem aquele interesse de aprender e fazer bem o trabalho. A pessoa sabe que o dinheiro não vai para o mesmo lugar, então ela não vai ter o mesmo interesse".

$\mathrm{O}$ fato de vários membros de uma mesma família estarem lutando em terras estrangeiras faz do sucesso um objetivo crucial, pois restam poucas pessoas no Brasil com quem contar em caso de prejuízo ou falência. Assim, familiares não estão dispostos a correr riscos e tendem a trabalhar com muito afinco e retidão e a ter mais tolerância com os problemas. Este estilo de trabalho só favorece as clientes americanas; daí seu apreço por sociedades familiares no housecleaning .

Dada uma sociedade, vejamos como ela funciona quanto às tarefas e pagamentos. Em geral, a divisão do trabalho é mais justa e flexível e o companheirismo mais corriqueiro do que entre dona do trabalho e ajudante. Ademais, as tarefas são divididas conforme as aptidões e preferências de cada uma: uma sócia pode tratar com as clientes porque domina melhor a língua, enquanto a outra faz a contabilidade porque no Brasil teve experiência similar. Os sócios ganham igualmente, mas aquele que dirige e mantém o carro recebe um acréscimo.

A sociedade pode terminar motivada por problemas de trabalho ou de relacionamento. Discordâncias em termos de estilo, ritmo, expectativas e prioridades fazem, com o tempo, as tensões intoleráveis e a sociedade é rompida. Brigas entre familiares, retornos para o Brasil e desonestidade entre os parceiros são motivos para deixar uma sociedade também. Salete recorda que sua "amiga" e primeira sócia tentou lhe "roubar" o schedule porque sabia mais inglês.

Durante o trabalho e nos momentos de sociabilidade da comunidade brasileira, as clientes são um dos assuntos mais comuns. Trocar experiências sobre o housecleaning é muito importante para estas profissionais que, em geral, trabalham sozinhas dentro das casas. Estas informações são fundamentais por incentivarem os primeiros alicerces coorporativos do ramo. Estas trocas capacitam estas cleaners para limitar a tendência exploradora de suas clientes e amenizar os estranhamentos culturais. Elas trocam informações sobre o mercado (preços, mão-de-obra disponível, concorrências de outras migrantes), tipos de clientes, serviço (produtos e técnicas de limpeza), dicas para o ramo (inglês, gasolina, gráficas para fazer as propagandas), etc.

Além disto, as housecleaners se divertem às custas das clientes: "porcarias", hábitos, roupas, alimentação, etc, encontrados nas casas americanas sempre inspiram os debates mais bem humorados. Jacklyn Cock lembra que "o silêncio ou a chacota secreta em relação aos empregadores talvez possa ser visto como rituais mudos de resistência. Eles envolvem uma forma de adaptação que permite que a empregada mantenha sua personalidade $\mathrm{e}$ integridade intactas em um papel inferiorizado" (Cock, 1981, p.74). A vida privada dos americanos motiva estranhamento, piadas e, no plano mais geral, uma aprendizagem acerca da cultura americana e, por comparação, da cultura brasileira.

\section{A COMPETIÇÃO ENTRE DONAS DO TRABALHO}

No entanto, freqüentemente, a relação entre donas do trabalho é de rivalidade e, principalmente, de competição. Quando uma cleaner conhece o trabalho de outra, ela vai comparar estilos e lucros para saber se seu trabalho está devidamente valorizado ou se precisa usar estas informações para "ganhar" ou limitar o trabalho de sua colega. Vejamos as maneiras pelas quais uma cleaner pode conhecer o trabalho alheio e como 
estas informações podem ser manipuladas.

As rodas de conversa são o cenário mais comum de avaliação do ramo: "se você vai numa festa e tá num grupinho, $\mathrm{o}$ assunto que sai é housecleaning. Eu conheço quem limpa bem e quem não limpa pelo jeito que elas falam que faz" (Graça). Depois, uma mesma ajudante pode ter trabalhado para duas cleaners diferentes. Sua maneira de limpar indica como era o estilo de trabalho da patroa anterior. Um terceiro meio de conhecer estilos concorrentes é ajudar a ajudante. Isto é, caso a ajudante seja dividida entre duas donas do trabalho simultaneamente, uma delas pode se tornar sua "ajudante" momentaneamente:

"Um dia eu fui ajudá-la a limpar uma dessas casas porque ela tava comigo e a patroa dela tinha ido no Brasil porque o pai tava passando mal. Depois das nossas, eu fui ajudar. Eu fiquei horrorizada. Ela falou, 'Clotilde, em cada cômodo que você entra, não vai passar pano em nada. Você passa o espanador e o vacuum ${ }^{8}$ só no meio'. Nós fizemos a casa enorme com uma hora. A mulher não troca essa Nara por ninguém. É a limpeza que ela conhece. Essa menina me ajuda três vezes na semana, só que ela ajuda outra pessoa dois dias. Ela não se conformava e me dizia, 'com a Nara, eu limpo seis casas no dia, com você eu não consigo limpar tudo isso!!" (Clotilde)

A quarta forma é uma dona do trabalho ajudar outra. Clotilde, madrasta de Gláucia, foi ajudá-la e relata a experiência:

"A Gláucia falou, 'Clotilde, pelo amor de deus, toda vez que a gente limpa aquele abajur ali, a cliente faz a minha mãe voltar de novo'. Fui lá e limpei. Como elas limpam eu não sei porque eu não perguntei. Nesse dia a mulher não mandou voltar. $O$ tempo inteiro a mulher olhando para mim. Limpei tudo e fomos embora. Passou uns dias, a Gláucia falou, 'Clotilde, agora aquela mulher tá querendo que você vai sem- pre comigo. Não quer que a minha mãe vai não. Minha mãe falou que isso não pode porque vocêtem as suas casas. Foi a primeira vez que não precisou voltar para limpar o abajur dela'."

Ao contrário do exemplo anterior em que a cliente de Nara não a deixaria por nenhuma outra housecleaner, a cliente de Gláucia ficou impressionada com Clotilde. Se uma dona do trabalho achar que seu trabalho é superior, ela pode voltar e propor àquela cliente mais trabalho por um preço menor. Clotilde poderia tentar "roubar" ambas as casas: não teria êxito com a primeira cliente, mas seria certo que a segunda cliente deixaria Gláucia e sua mãe.

Uma quinta forma de conhecer o trabalho de outras cleaners é pela substituição temporária ou permanente. Quando uma cleaner empresta, dá ou vende seu schedule para outra brasileira, esta vai notar como o trabalho era feito.

Como é seu objetivo, a propaganda anuncia o trabalho. Os flyers $^{9}$, cartões e cartas distribuídas nas casas americanas indicam preço, tipo de serviço e contatos da proponente. Algumas cleaners, como Salete, eliminam qualquer concorrência antes que suas clientes a vejam. Eva reage ao contrário: "Os cartõezinhos que eu acho deixo no mesmo lugar. E o respeito pelas minhas colegas? Se eu consegui por cartão por que elas não podem conseguir? Não tem nada a ver, isso aqui é um campo profissional aberto a todos, ganha quem é melhor". A concorrência pode desestabilizar a relação entre cliente e cleaner ou, ao contrário, confirmar a opinião da primeira e o mérito da segunda. A propaganda pode ser oral e direta:

"Há uns seis ou sete meses, no verão que passou, a cliente tava brincando com os meninos na frente da casa e passou um carro com uns brasileiros, um homem e uma mulher. Eles perguntaram se ela precisava de uma housecleaner. Ela falou que não, que ela já tinha. Eles perguntaram quanto que ela paga. Ela falou, '100 dólares'. 'Nos- sa, é muito. Eu faço a sua casa por 40 dólares'. Ela riu e falou, 'não, eu gosto muito de quem limpa a minha casa'. Ela virou para mim e contou". (Eunice)

Ou ainda, a propaganda pode ser a própria prática. Muitas cleaners fazem o free estimate, isto é, conhecem a casa da potencial cliente e anunciam o preço ou, nesta mesma visita, dão uma amostra do trabalho. Alice e sua mãe, Ângela, limpavam uma casa por 70 dólares. Um dia, Ângela encontrou, na porta da geladeira, um flyer de outra cleaner oferecendo a limpeza por 55 dólares. As sócias perceberam como era o trabalho da concorrente não só pelo preço cobrado, mas, sobretudo, pela limpeza realizada. E o fato da cliente não ter dispensado mãe e filha, fez Alice concluir que a cliente além de preferir seu trabalho passou a valorizá-lo ainda mais.

Conhecer a concorrência é importante para saber se o próprio trabalho está dentro das margens ideais de lucro, serviço e tempo. A partir daí, a housecleaner decide se deve oferecer um trabalho padronizado ou acoplar um diferencial para desbancar a concorrência. Este diferencial pode compreender a quantidade e/ou a qualidade das tarefas, o preço e a relação com a cliente.

Ao conhecer a concorrência, a housecleaner pode simplesmente valorizar seu próprio trabalho ou pode tentar limitar esta concorrência de variadas formas. Como foi adiantado acima, ela pode "roubar" casas alheias, pode destruir propagandas que encontra, pode difamar seu nome, pode passar casas problemáticas propositadamente para que ela desanime do ramo, pode boicotar a concorrente sonegando informações sobre o ramo ou evitando lhe "dar" casas quando precisa aumentar seu schedule.

No final, a concorrência limita a diversidade de estilos de faxina oferecidos. O medo de serem substituídas por cleaners brasileiras ou, em geral, russas, hispânicas, orientais, que, por menos fazem bem mais, é grande e intimida qualquer resistência às vontades extra- 
vagantes das clientes. Com isso, a clientela deixa que as forças do mercado regulem as condições de trabalho e se exime, convenientemente, das negociações. Este mesmo medo é o que gera a rivalidade entre compatriotas e resulta em variados golpes, práticas justificadas unicamente em prol dos objetivos individualistas da migração.

\section{CONSIDERAÇÕES FINAIS}

Este artigo pretendeu ilustrar a possibilidade de interações cooperativas e competitivas entre duas brasileiras numa relação horizontal, isto é, com papéis e status similares no housecleaning. As relações entre duas donas do trabalho se assemelham aos arranjos entre duas ajudantes ou duas clientes, isto é, há sempre duas possibilidades de interação. Elas se auxiliam ou concorrem em prol do trabalho e/ou em relação a um terceiro personagem. Enquanto que, as relações entre cliente e dona do trabalho (Fleischer, 2000a), cliente e ajudante e dona do trabalho e ajudante são todas verticais, hierárquicas e desiguais. O espaço para negociação é menor, a frustração e o rompimento são mais comuns e drásticos e as chances de antagonismo são mais imediatas. Esta verticalidade se atenua um pouco quando duas partes se unem para fazer frente à dominação de uma terceira. É muito comum dona do trabalho e ajudante boicotarem conjuntamente uma cliente discriminadora, bagunceira ou mal pagadora, por exemplo.

Em Boston, havia exemplos de atmosferas de trabalho tranqüilas tanto com clientes, sócias, concorrentes e subordinadas. Isto dependia do estilo de trabalho, do momento do schedule e dos objetivos da migração. Em geral, nos primeiros anos, os migrantes competem em "busca do ouro" (Sales, 1999).

Acredito que, assim como outros grupos étnicos, quando a comunidade brasileira se estabelecer economicamente e tiver sua identidade cultural mais consolidada, vai constituir realmente uma comunidade étnica. Então, a coesão e a coerção social serão mais intensas e a solidariedade uma consequiência possível. Ao contrário de outras nacionalidades, os brasileiros, até o final de século, não haviam tido experiências como emigrantes internacionais e, portanto, no momento, estão, não só construindo a história destas trajetórias, como também o significado da palavra migrante. E o cenário multiétnico em que os EUA vêm se transformando será um contraponto fundamental para esta comunidade brasileira se espelhar e compreender. Assim, talvez, os emigrantes brasileiros, desafiados pelo cosmopolitanismo e pelas novas relações de trabalho, estejam encabeçando a criação de uma nova vertente da identidade brasileira onde coletividade, cooperação e, quiçá, solidariedade ganhem novos significados. Talvez seja olhando para o Brasil lá de fora que o Brasil aqui de dentro encontre soluções mais criativas para seus tantos problemas.

* Soraya Fleischer é antropóloga e pesquisadora da ONG socioambiental Instituto Sociedade, População e Natureza (ISPN).

\section{NOTAS}

1 - Pelo fato das entrevistadas, e dos brasileiros em geral, falarem um português repleto de palavras e expressōes em inglês ou adaptadas do inglês, optei por reproduzir o mais fielmente possivel este mélange lingüístico e incorporar os termos ao texto. Estes estarão em itálico enquanto a ênfase estará em negrito.

2 - Baby-sitter é babá de crianças e dishwasher é quem lava pratos num restaurante ou bar (o termo foi aportuguesado na comunidade brasileira como "dicha").

3- Grade horária semanal sobre a qual, no caso do housecleaning, são organizadas as casas a serem limpas.

4 - Esta prática foi observada e comentada por outros autores também. Para maiores detalhes e curiosidades, ver Martes (2000), Fleischer (2000b), Margolis (1994), Ribeiro (1998).

5 - Documento expedido pelo Immigration and Naturalization Service (INS) que permite a permanência legal e continuada de estrangeiros nos EUA.

6 - Migrante que permaneceu no exterior após a data de validade do seu visto de turista que, no caso brasileiro, geralmente é concedido por três meses.
7 - Os nomes das entrevistadas são fictícios para garantir a privacidade e a segurança destas migrantes, muitas vezes ilegais em solo norte-americano e temerosas desta situação vulnerável e desconfortável.

8 - Vacuum cleaner ou, abreviadamente, vacuum é aspirador de pó.

9 - Panfleto de divulgação de algum evento ou serviço.

\section{REFERÊNCIAS BIBLIOGRÁFICAS}

\section{ASSIS, Gláucia de Oliveira}

(1999) “Estar Aqui, Estar Lá: uma cartografia da emigração valadarense para os EUA". In: REIS, R. Rocha e SALES, Teresa. Cenas de um Brasil migrante. São Paulo, Boitempo Editorial, p.125.

COCK, Jacklyn

(1981) "Disposable nannies: domestic servants in the political economy of South Africa". Review of African Political Economy, n. 21, maio-setembro.

FLEISCHER, Soraya

(2000a) "O trabalho de emigrantes brasileiras: conflitos entre housecleaners brasileiras e suas clientes americanas". Em busca da experiência mundana e seus significados: Georg Simmel, Alfred Schutz e a Antropologia. Rio de Janeiro, Relume Dumará, p. 167.

FLEISCHER, Soraya

(2000b) Passando a América a limpo: $O$ trabalho de housecleaners brasileiras em Boston, Massachussets. Dissertação de mestrado em Antropologia Social, PPGAS/ Universidade de Brasília.

MARGOLIS, Maxine

(1994) Little Brazil. Princeton, Princeton University Press.

MARTES, Ana Cristina Braga

(2000) Brasileiros nos Estados Unidos: um estudo sobre imigrantes em Massachusetts. São Paulo, Paz e Terra.

RIBEIRO, Gustavo Lins

(1998) "O que faz o Brasil, Brazil: jogos identitários em São Francisco". Série Antropologia n. 237, Universidade de Brasilia.

SALES, Teresa

(1999) Brasileiros Longe de Casa. São Paulo, Editora Cortes.

SASAKI, Elisa M.

(1999) "Movimento dekassegui: a experiência migratória e identitária dos brasileiros descendentes de japoneses no Japão". In: REIS, R. Rocha e SALES, Teresa. Cenas de um Brasil migrante. São Paulo, Boitempo Editorial, p. 243.

TORRESAN, Angela Maria de Souza (1994) Quem parte e quem fica: uma etnografia sobre imigrantes brasileiros em Londres. Dissertação de mestrado em Antropologia Social, PPGAS/ Museu Nacional, UFRJ. 